\title{
Spina Bifida Occulta Causing Plantar Ulceration*
}

\author{
D. S. CHAUDHURY† \\ Le prosy Service, Ministry of Health, Ghana
}

\begin{abstract}
The differential diagnosis of the underlying cause of plantar ulceration will include such well-recognized conditions as diabetes and yaws, and the relatively rare diseases of tabes dorsalis and syringomyelia. Plantar ulcer is the commonest serious foot lesion associated with leprosy, but anaesthesia and intrinsic muscle paralysis due to other diseases causing nerve damage must always be remembered. The following history of chronic plantar ulcer in a boy aged 16 years serves as a salutary reminder of this fact.
\end{abstract}

A deep plantar ulcer, $3 \mathrm{~cm}$ in diam., was present on the right heel (Fig. 1). Its base was clean and covered with thin granulation tissue. The sole of the foot was flattened, the foot being inverted (Fig. 2). There was loss of sensation to light touch, pin-prick, and thermal stimulation in the skin around the ankle and the outer aspect of the heel. No leprosy lesions were found in the skin, and all the peripheral nerves were normal. The Achilles tendon was shortened. There was no family history of leprosy. The patient was said to have started walking late and in a clumsy way.

Radiological examination showed early rarefaction of the os calcis. When the patient was stripped, a tuft of hair was noticed over the 4th and 5th lumbar vertebrae (Fig. 3). A small depression, suggestive of an underlying bony defect, was palpated at this site and confirmed by radiological examination, which showed defects of the 5th lumbar vertebra and the upper margin of the sacrum. There was pronounced atrophy of the glutei and of the muscles of the right thigh and leg. There was

*Received for publication 10, August, 1970.

†Address: Ghana Leprosy Service, Ministry of Health, P.O. Box 26, Elmina, Ghana. marked scoliosis, and knee and ankle jerks on the affected side were diminished. Bowel and bladder functions were normal. The results of laboratory investigations were as follows:

(1) Skin smears for Myco. leprae

Negative

(2) Swab from ulcer, examined for Myco. leprae.

(3) Wassermann reaction .

Negative

(4) Lepromin test (Mitsuda reaction) .

Negative

$.10 \mathrm{~mm}$

The case was, therefore, diagnosed as spina bifida occulta. In this condition the vertebral arches fail to fuse, but there is no protrusion of the coverings of the cord. The defect is usually occupied by fibrous tissue to which the cord or dura is adherent and which is itself attached to the skin. As the bony vertebral column grows in length, traction is exerted on the cord, leading to paralyses and neuropathic ulcerations of various kinds.

\section{ACKNOWLEDGEMENT}

Grateful acknowledgements are due to the Director of Medical Services, Ghana, for kind permission to report this case. 


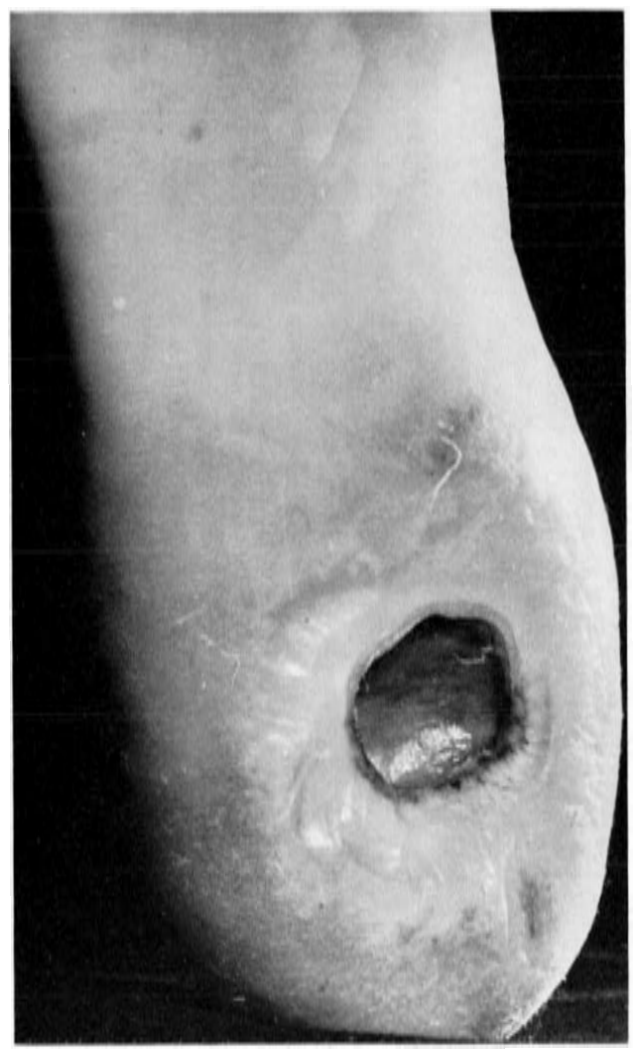

FIG. 1

Plantar ulcer on the right heel.

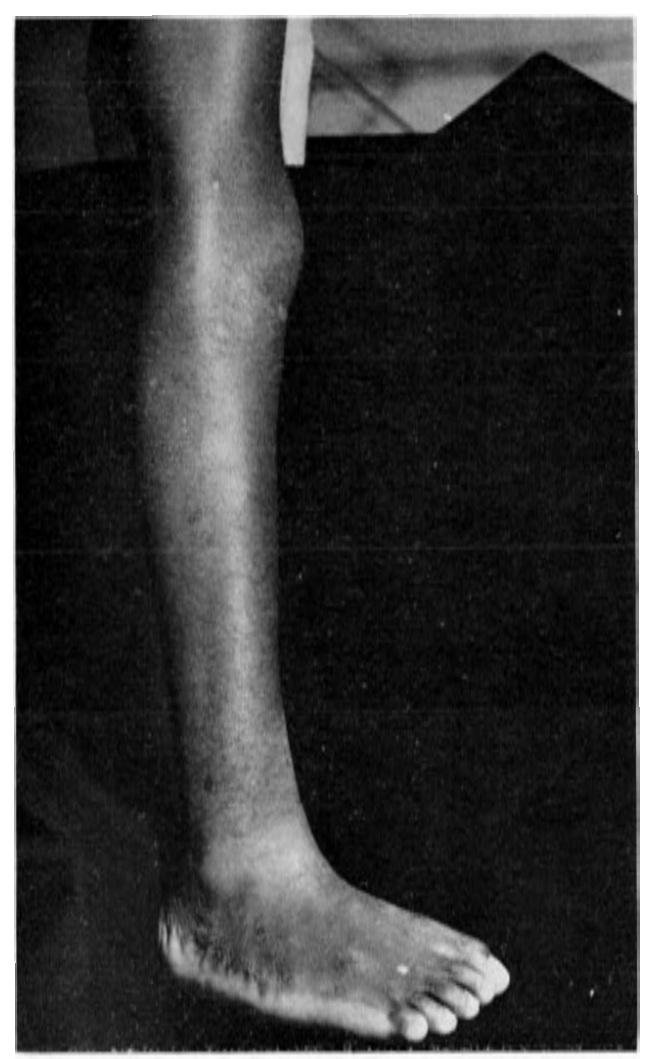

FIG. 2

Right foot inverted with dropping of the big toe.

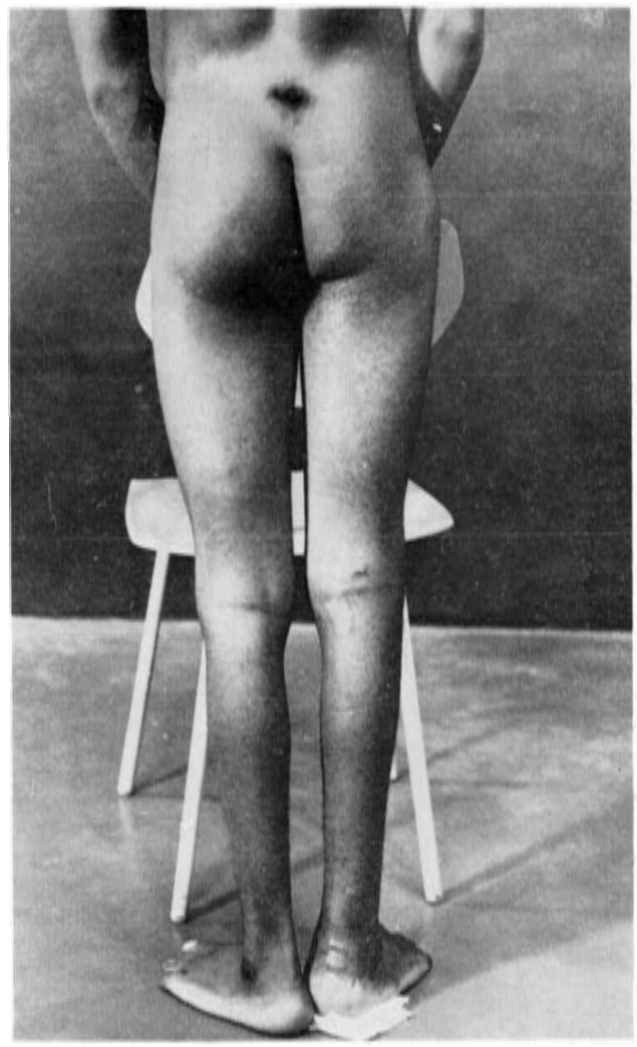

FIG. 3

The back of the patient showing tuft of hair over the lumbosacral area, atrophy of the right hip, thigh and leg muscles and swelling of the right ankle. 